Pacific Journal of Mathematics

SELF-INTERSECTION OF A SPHERE ON A COMPLEX 


\section{SELF-INTERSECTION OF A SPHERE ON A COMPLEX QUADRIC}

\section{FÁRY}

1. The real part $S^{n}$ of a quadric $V$ in complex, affine $(n+1)$-space is a sphere. The self-intersection of $S^{n}$ in $V$ is the same as the selfintersection of a "vanishing cycle," introduced by Lefschetz, and plays a certain role in [4], [5]. We will compute here this self-intersection number, using elementary tools.

Let us introduce some notations. $P_{n+1}$ denotes the complex projective space of algebraic dimension $n+1$, hence of topological dimension

$$
\operatorname{dim} P_{n+1}=2 n+2 \text {. }
$$

To each projective sub-space $P_{k}$ of $P_{n+1}$ a positive orientation can be given, thus it can be considered as a cycle $p_{2 k}$. Then we agree that

$$
\text { if } k+l=n_{i}+1 \text {, then }\left(p_{2 k}, p_{2 l}\right)=1 \text { in } P_{n+1}
$$

be true for the intersection numbers of cycles. This is the usual convention, the one in [1], for example; in [7] another convention is adopted.

Let $x_{1}, \cdots, x_{n+2}$ be a fixed system of projective coordinates in $P_{n+1}$. Then

$$
Q_{n}: x_{1}^{2}+\cdots+x_{n+2}^{2}=0
$$

is a non-singular quadric; $\operatorname{dim} Q_{n}=2 n$. The points of $P_{n+1}$ whose last coordinate is non-zero form a complex affine space $C_{n+1}$, and

$$
V=Q_{n} \cap C_{n+1}=\left[x: x \in Q_{n}, x_{n+2} \neq 0\right]
$$

is a non-singular affine quadric. If $z \in C_{n+1}$, we denote by $z_{1}, \cdots, z_{n+2}$ those coordinates for which $z_{n+2}=i$ where $i^{2}=-1$; thus $z_{1}, \cdots, z_{n+1}$ are affine coordinates in $C_{n+1}$. Then

$$
\begin{array}{ll}
V: & z_{1}^{2}+\cdots+z_{n+1}^{2}=1 \\
S^{n}: & z_{1}^{2}+\cdots+z_{n+1}^{2}=1, z_{1} \cdots, z_{n+1} \text { reals }
\end{array} \quad\left(z \in C_{n+1}\right)
$$

are the equations of an affine quadric and its real part respectively; this real part $S^{n}$ is, of course, a sphere. We consider $S^{n}$ with an arbitrarily chosen and fixed orientation as a cycle $s$. It is well known (see, for example, [2], p. 35, (g)) that 
(3) the homology class $s$, of the cycle whose carrier is $S^{n}$, generates $H_{n}(V ; Z)$,

where $Z$ denotes the ring of integers.

As $\operatorname{dim} V=2 \operatorname{dim} S^{n}$, the self intersection number

$$
(s, s)=\left(S^{n} S^{n}\right),
$$

(in $V$ ),

of $s$ in $V$, is well defined; we may write $\left(S^{n}, S^{n}\right)$ for this self intersection number, because $(s, s)$ does not depend on the orientation of $S^{n}$, used in (3).

2. M. F. Atiyah communicated to me his computation of the intersection number (4) for $n=2$, showing that the sign in [2], p. 35 (10) is not the right one. ${ }^{1}$ The determination of the sign of (4) given below is a generalization to $n$ dimensions of the construction of Atiyah. In [2] we used only the fact that (4) is not zero, if $n$ is even, hence other results of that paper are not invalidated by the false sign in (10), p. 35 . The mistaken sign is "classical." Wrong sign appears in [4], p. 93, Théorème sur les $\Gamma_{a-1}$ de $C_{u}, I$, [5] on top of p. 16, [8], p. 102, (3), and [7], p. 104, Theorem 45 (although in [7] not the convention (1) is used, the alternation of the sign in question is independent of any convention). After the completion of the present paper [6] appeared, where the classical mistake in sign is corrected (see (11.3) on p. 161). The results of [1] are in agreement with the sign (5) below.

3. Using the notations and conventions introduced above, we will prove the following theorem.

THEOREM. Let $s$ be the homology class of the oriented sphere $S^{n}$ in $H_{n}\left(Q_{n} ; Z\right)$ where $n=2 h$ is even. Let us denote by $(s, s)$ the selfintersection number of s computed with the convention (1). Then

$$
(s, s)=\left\{\begin{array}{l}
-2, \text { if } h=\frac{n}{2} \text { is odd } ; \\
+2, \text { if } h=\frac{n}{2} \text { is even } ;
\end{array}\right.
$$

holds true.

1 I take the opportunity to correct another mistake in [2], also noticed by Atiyah. In Proposition 2, p. 27, we have to suppose that the singularity in question is conical. In [2], Proposition 2 is stated without proof; Atiyah gave an example showing that the statement does not hold true, if the singularity is not conical, and gave a proof with the correct hypothesis. Proposition 2 is used in [2] only in connection with conical singularities; thus other results of [2] are not affected by the incomplete formulation of that Proposition. 
4. We prepare the proof of this theorem; for the first part of the proof, see [1]. (See also [3], pp. 230-232.) In order to describe easily linear sub-spaces of $Q_{n}$, we introduce new projective coordinates in $P_{n+1}$ :

$$
\begin{aligned}
& u_{j}=x_{2 j-1}+i x_{2 j} \\
& v_{j}=x_{2 j-1}-i x_{2 j}
\end{aligned} ;=1, \cdots, h+1
$$

Let us notice that

$$
u_{j}=v_{j}=0 \text { if and only if } x_{2 j-1}=x_{2 j}=0 .
$$

The equation of $Q_{n}$ is

$$
u_{1} v_{1}+\cdots+u_{h+1} v_{h+1}=0,
$$

in the new coordinates.

We consider the following linear sub-spaces of $Q_{n}$ :

$$
\begin{array}{ll}
A: & u_{j}=0, \quad j=1, \cdots, h, h+1 ; \\
B: & u_{j}=0, \quad j=1, \cdots, h ; v_{h+1}=0 ; \\
C: & v_{j}=0, \quad j=1, \cdots, h+1 .
\end{array}
$$

Let us remark that,

$$
A \cap C=\phi, \quad B \cap C \text { is just one point, }
$$

by (6).

Lemma 1. Let $X$ be one of the projective spaces $A, B, C$. If, in the system of equations defining $X$, we replace an even number of equations $u_{j}=0$ by the corresponding $v_{j}=0$, or vice versa, we define a new linear sub-space of $Q_{n}$ belonging to the same continuous system as $X$. Similarly, without leaving the continuous system containing $B$, we may replace $u_{h}=0, v_{h+1}=0$ in (8) by $v_{h}=0$ and $u_{h+1}=0$.

Proof. Let us suppose that we want to replace $v_{1}=0, v_{2}=0$ in (9) by $u_{1}=0, u_{2}=0$. Let us consider the linear space

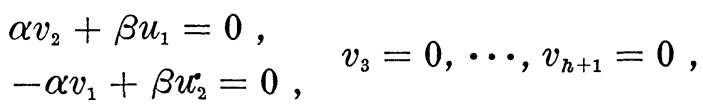

defined for every $(\alpha, \beta) \neq(0,0)$. This projective space is clearly contained in $Q_{n}$. For $(1,0)$ we have $C$ and for $(0,1)$ the desired replacement. The last statement of the lemma is proved similarly using the system

$$
\begin{aligned}
& \alpha u_{h}+\beta u_{h+1}=0, \\
& -\beta v_{h}+a v_{h+1}=0 .
\end{aligned}
$$


Let us consider now $A, B, C$ as cycles of $Q_{n}$, and let us denote by $a, b, c$ their respective homology classes in $H_{n}\left(Q_{n} ; Z\right)$.

Lemma 2. If $h$ is odd, then $c=a$. If $h$ is even, then $c=b$.

Proof. If $h$ is odd, the $h+1$ equations of (9) can be replaced by the equations $u_{j}=0, j=1, \cdots, h+1$. Hence $A$ and $C$ belong to the same continuous system. If $h$ is even, we can replace the first $h$ equations defining $C$ by $u_{j}=0, j=1, \cdots, h$. Hence $C$ and $B$ belong to the same continuous system.

Lemma 3. As to the intersection numbers, we have

$$
\begin{aligned}
& \text { if } h \text { is odd, then }(a, a)=0,(b, b)=0,(a, b)=1, \\
& \text { if } h \text { is even, then }(a, a)=1,(b, b)=1,(a, b)=0 .
\end{aligned}
$$

Proof. (1) Let $h$ be odd. By Lemma 2 and the first equation of (10), we have $(a, a)=0$. Similarly, the second equation of (10) and Lemma 2 prove $(a, b)=1$. In order to prove $(b, b)=0$, we consider the space

$$
B^{\prime}: \quad v_{j}=0, \quad j=1, \cdots, h, \quad u_{h+1}=0 .
$$

We claim that $B$ and $B^{\prime}$ are in the same continuous system. In order to prove this statement, we use Lemma 1 twice. First, we replace the last two equations of (8) by $v_{h}=0$, and $u_{h+1}=0$. Second, in the system obtained by the first step, we replace the first $h-1$ equations by $v_{j}=0$. Now $B \cap B^{\prime}=\phi$, and this proves $(b, b)=0$.

(2) Let $h$ be even. The proof of (12) is similar to the previous one. The last two equations of (12) are immediate from (10) and Lemma 2. Using Lemma 1 , we can find presently $a B^{\prime \prime}$, such that $B \cap B^{\prime \prime}$ be just one point.

LEMma 4. Using the previous notations $s, a, b$, for homology' classes,

$$
s= \pm(a-b),
$$

the sign depending on the chosen orientation of $S^{n}$.

Proof. Let us denote by $I$ the hyperplane $x_{n+2}=0$, Then, clearly,

$$
A \cap I=B \cap I \text {. }
$$

We denote by $J$ this intersection $(J=A \cap B)$. Let us consider a pencil 
of $k$-planes, $2 k+\operatorname{dim} A=2 n+2$, in general position. If $N$ is a neighborhood of $J$ in $B$, the $k$-planes of the pencil project $N$ into a neighborhood $M$ of $J$ in $A$. Given now a Riemann metric of $P_{n+1}$, if $N$ is a small enough neighborhood of $J$, the corresponding points of $N, M$ determine unique geodesic segments. We consider now $B$ as a cycle, whose simplexes are so small that those intersecting $J$ are contained in $N$. Using the geodesic segments introduced above which start at points of the simplexes of $B$ intersecting $J$, it is easy to construct a chain $E$ of $Q_{n}$, such that

$$
A-B+\partial E
$$

be a sum of simplexes of $V=Q_{n}-I$. Hence, $s$ being a generator of $H_{n}(V ; Z)$, (14) will be homologous to a multiple of $s$. Thus $a-b=m s$ for some integer $m$. Now $(a-b, a)=m(s, a)$ is \pm 1 by Lemma 3 , hence $m= \pm 1$.

Proof of the Theorem. (1) Let us suppose that $h$ is odd. We use (13) and (11): $(s, s)=(a-b, a-b)=(a, a)-(b, a)-(a, b)+(b, b)$ $=-(b, a)-(a, b)=-2$.

(2) Let us suppose that $h$ is even. This time we use (12): $(s, s)$ $=(a, a)+(b, b)=+2$. Hence the proof of (5) is complete.

\section{REFERENCES}

1. É. Cartan, Sur les propriétés topologiques des quadriques complexes, Publications Mathématiques de 1'Université de Belgrade, 1 (1932), 1-20.

2. I. Fáry, Cohomologie des variétés algébriques, Annals of Math. 65 (1957), 21-73.

3. Hodge and Pedoe, Methods of Algebraic Geometry, Vol. II, Cambridge University Press, 1954.

4. S. Lefschetz, L'Analysis Situs et la Géométrie Algébrique, Paris, Gathier-Villars, 1924.

5. — Géométrie sur les surfaces et les variétés algébriques, Mémorial des Sciences Mathématiques, Fasc. XL, Paris, Gauthier-Villars, 1929.

6. J. Leray, Le calcul différentiel et intégral sur une variété analytique complexe (Problème de Cauchy, III), Bulletin de la Soiété Mathématique de France, 87 (1959), 81-180.

7. A. H. Wallace, Homology Theory on Algebraic Varieties, New York, Pergamon Press, 1958.

8. O. Zariski, Algebraic Surfaces, Berlin, 1935, Springer Verlag.

University of CALIFornia, Berkeley 



\section{PACIFIC JOURNAL OF MATHEMATICS}

\section{EDITORS}

\author{
RaLPh S. Phillips \\ Stanford University \\ Stanford, California \\ F. H. BRowNELL \\ University of Washington \\ Seattle 5 , Washington
}

A. L. Whiteman

University of Southern California

Los Angeles 7, California

L. J. Paige

University of California

Los Angeles 24, California

\author{
E. F. BECKENBACH \\ T. M. CHERRY
}

\author{
ASSOCIATE EDITORS

$\begin{array}{lll}\text { D. DERRY } & \text { H. L. ROYDEN } & \text { E. G. STRAUS } \\ \text { M. OHTSUKA } & \text { E. SPANIER } & \text { F. WOLF }\end{array}$

\section{SUPPORTING INSTITUTIONS}

\author{
UNIVERSITY OF BRITISH COLUMBIA \\ CALIFORNIA INSTITUTE OF TECHNOLOGY \\ UNIVERSITY OF CALIFORNIA \\ MONTANA STATE UNIVERSITY \\ UNIVERSITY OF NEVADA \\ NEW MEXICO STATE UNIVERSITY \\ OREGON STATE COLLEGE \\ UNIVERSITY OF OREGON \\ OSAKA UNIVERSITY \\ UNIVERSITY OF SOUTHERN CALIFORNIA
}

\author{
STANFORD UNIVERSITY \\ UNIVERSITY OF TOKYO \\ UNIVERSITY OF UTAH \\ WASHINGTON STATE COLLEGE \\ UNIVERSITY OF WASHINGTON \\ AMERICAN MATHEMATICAL SOCIETY \\ CALIFORNIA RESEARCH CORPORATION \\ HUGHES AIRCRAFT COMPANY \\ SPACE TECHNOLOGY LABORATORIES \\ NAVAL ORDNANCE TEST STATION
}

Mathematical papers intended for publication in the Pacific Journal of Mathematics should be typewritten (double spaced), and the author should keep a complete copy. Manuscripts may be sent to any one of the four editors. All other communications to the editors should be addressed to the managing editor, L. J. Paige at the University of California, Los Angeles 24, California.

50 reprints per author of each article are furnished free of charge; additional copies may be obtained at cost in multiples of 50 .

The Pacific Journal of Mathematics is published quarterly, in March, June, September, and December. The price per volume (4 numbers) is $\$ 12.00$; single issues, $\$ 3.50$. Back numbers are available. Special price to individual faculty members of supporting institutions and to individual members of the American Mathematical Society: $\$ 4.00$ per volume; single issues, $\$ 1.25$.

Subscriptions, orders for back numbers, and changes of address should be sent to Pacific Journal of Mathematics, 103 Highland Boulevard, Berkeley 8, California.

Printed at Kokusai Bunken Insatsusha (International Academic Printing Co., Ltd.), No. 6, 2-chome, Fujimi-cho, Chiyoda-ku, Tokyo, Japan.

\section{PUBLISHED BY PACIFIC JOURNAL OF MATHEMATICS, A NON-PROFIT CORPORATION}

The Supporting Institutions listed above contribute to the cost of publication of this Journal, but they are not owners or publishers and have no responsibility for its content or policies.

Reprinted 1966 in the United States of America 


\section{Pacific Journal of Mathematics}

\section{Vol. 11, No. 4}

A. V. Balakrishnan, Prediction theory for Markoff processes . . . . . . . . . . 1171

Dallas O. Banks, Upper bounds for the eigenvalues of some vibrating systems . . . . 1183

A. Białynicki-Birula, On the field of rational functions of algebraic groups ...... 1205

Thomas Andrew Brown, Simple paths on convex polyhedra .............. 1211

L. Carlitz, Some congruences for the Bell polynomials . . . . . . . . . . . . 1215

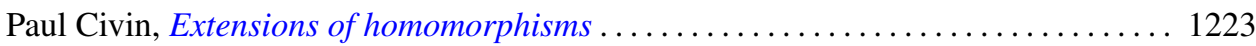

Paul Joseph Cohen and Milton Lees, Asymptotic decay of solutions of differential

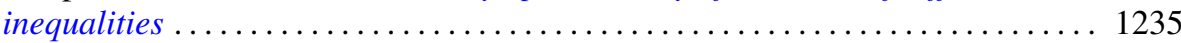

István Fáry, Self-intersection of a sphere on a complex quadric . . . . . . . . . . 1251

Walter Feit and John Griggs Thompson, Groups which have a faithful representation

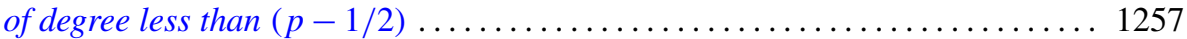

William James Firey, Mean cross-section measures of harmonic means of convex

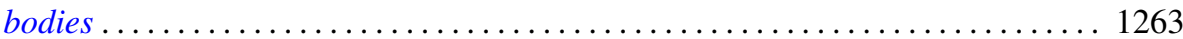

Avner Friedman, The wave equation for differential forms . . . . . . . . . . 1267

Bernard Russel Gelbaum and Jesus Gil De Lamadrid, Bases of tensor products of

Banach spaces ................................... 1281

Ronald Kay Getoor, Infinitely divisible probabilities on the hyperbolic plane . . . . 1287

Basil Gordon, Sequences in groups with distinct partial products . . . . . . . . . . . . 1309

Magnus R. Hestenes, Relative self-adjoint operators in Hilbert space . . . . . . . . . 1315

Fu Cheng Hsiang, On a theorem of Fejér ......................... 1359

John McCormick Irwin and Elbert A. Walker, On N-high subgroups of Abelian

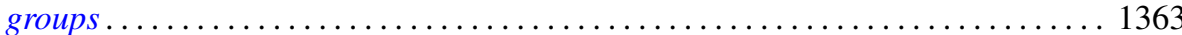

John McCormick Irwin, High subgroups of Abelian torsion groups . . . . . . . . . 1375

R. E. Johnson, Quotient rings of rings with zero singular ideal . . . . . . . . . . . 1385

David G. Kendall and John Leonard Mott, The asymptotic distribution of the time-to-escape for comets strongly bound to the solar system ...

Kurt Kreith, The spectrum of singular self-adjoint elliptic operators ....

Lionello Lombardi, The semicontinuity of the most general integral of the calculus of variations in non-parametric form ................................

Albert W. Marshall and Ingram Olkin, Game theoretic proof that Chebyshev inequalities are sharp

Wallace Smith Martindale, III, Primitive algebras with involution . . William H. Mills, Decomposition of holomorphs ..............

James Donald Monk, On the representation theory for cylindric algebras . . . . . . 1447

Shu-Teh Chen Moy, A note on generalizations of Shannon-McMillan theorem . . . . 1459

Donald Earl Myers, An imbedding space for Schwartz distributions . .

John R. Myhill, Category methods in recursion theory .........

Paul Adrian Nickel, On extremal properties for annular radial and circular slit mappings of bordered Riemann surfaces

Edward Scott O'Keefe, Primal clusters of two-element algebras . .

Nelson Onuchic, Applications of the topological method of Wazewski to certain

problems of asymptotic behavior in ordinary differential equations ...

Peter Perkins, A theorem on regular matrices................

Clinton M. Petty, Centroid surfaces .... 